\title{
Physiological Responses of the Ark Shell Scapharca broughtonii (Bivalvia: Arcidae) to Decreases in Salinity
}

\author{
Yun Kyung Shin*, Byung Hak Kim, Bong Se Oh, Choon Goo Jung', \\ Sang Gyu Sohn' and Jung Sick Lee ${ }^{2}$ \\ Shellfish Research Center, NFRDI, 668-821, Korea \\ ${ }^{1}$ South Sea Fisheries Research Institute, NFRDI, 556-823, Korea \\ ${ }^{2}$ Chonnam National University, Yeosu, 550-749, Korea
}

\begin{abstract}
The ark shell (or "blood clam") Scapharca broughtonii is a filter-feeding bivalve that has red blood and inhabits waters approximately $10 \mathrm{~m}$ in depth off the southern coast of South Korea. This study was part of a larger research project investigating the causes of death and restoration of shellfish resources, which are important aquaculture products in South Korea. We examined physiological responses related to survival, respiration, excretion, and amino acid changes as a result of changes in salinity. The 9-day median lethal salinity $\left(\mathrm{LS}_{50}\right)$ was 16.5 psu with confidence limits of 14.9-18.1 psu. At $25^{\circ} \mathrm{C}$, the oxygen consumption and ammonia-nitrogen excretion rates were increased with decreases in salinity. Although the osmolality of individuals was acclimated within $2 \mathrm{~h}$ at $26.4 \mathrm{psu}$ and $12 \mathrm{~h}$ at $19.8 \mathrm{psu}$, it took more than 5 days at a salinity of $13.2 \mathrm{psu}$, whereas no individuals acclimated and all died at a salinity of $6.6 \mathrm{psu}$. Of the amino acids present in the blood, taurine and alanine increased in response to decreased salinity. Tissues of the gill and the mid-gut gland were affected by decreasing salinity. These data will provide important fundamental information for examining the causes of mass mortality of shellfish in the summer.
\end{abstract}

Key words: Scapharca broughtonii, Salinity, Survival, Amino acid, Osmolality, Gill, Mid-gut gland

\section{Introduction}

Temperature and salinity are important physical factors that determine the geological distributions and affect the lives of marine organisms (Kinne, 1966). In coastal areas, changes in salinity vary among seasons, and responses to even short-term changes in salinity vary widely among organisms. The majority of shellfishes are isosmotic within a range of $50-150 \%$ seawater (Tucker, 1970); physiological changes in the heartbeat, pattern of oxygen consumption, and excretion of ammonia and amino acids accompany a reduction in salinity (Pierce and Greenberg, 1972). In addition, changes in salinity alter the status of the balance between the water content of tissues and the influx and efflux of salts. When salinity changes rapidly, shellfish exhibit an immediate behavioral response in which the shell is closed to minimize reductions in metabolic rate related to increases in

*Corresponding author: ykshin@nfrda.re.kr cellular volume. Thus, studies of shellfish responses to changing salinity are important to obtain information that will support the production of seedlings and management of cultured organisms.

The ark shell Scapharca broughtonii belongs to the family Arcidae and is distributed in countries with latitudes similar to those of South Korea, including Japan and China, where the species is cultivated commercially. The production of this clam in South Korea peaked in 1998. Yields have decreased gradually since 1998, with a current annual survival rate of $3-5 \%$, necessitating urgent efforts to examine the causes of death and decrease in the productivity of this mollusk. This study was a part of research into the causes of death and restoration of $S$. broughtonii, which is an important aquaculture product in South Korea. We examined physiological responses related to survival, respiration, excretion, and amino acid changes as a result of changes in salinity. 


\section{Materials and Methods}

Ark shells were collected from Kamak Bay, near Yosu, Jeonnam Province, South Korea, transferred to the laboratory, cultivated in 5-ton water tanks, and used in experiments after acclimating to the experimental water temperature for 2 weeks. A mixture of Isochrysis galbana, Pavlova sp., and Chaetoceros sp., which were cultured in large quantities in the laboratory, was supplied as feed during the experimental period. The experimental water temperature was $25 \pm$ $0.5^{\circ} \mathrm{C}$, and the experimental salinities were $33.0 \mathrm{psu}$ (ordinary seawater), 26.4, 19.8, 13.2, and $6.6 \pm 0.5 \mathrm{psu}$. Illumination was provided at $12 \mathrm{~h}$ light: $12 \mathrm{~h}$ dark. The ark shells used in the experiment had an average shell length of $69.6 \pm 5 \mathrm{~mm}$ and an average weight of $88.8 \pm 12.9 \mathrm{~g}$. All experiments were conducted for 9 days in circulation filtration format. An automatic salinity gauge (PR-100SA; Atago, South Korea) was used to measure salinity.

The survival rate was determined from the number of individuals that survived over the duration of each experiment. The oxygen consumption rates $\left(\mathrm{mg} \mathrm{O}_{2} / \mathrm{g}\right.$ wet wt./h) of $S$. broughtonii were measured in respirometer chambers containing natural fresh water near full oxygen saturation. The chambers were immersed in a temperature-controlled water bath to maintain a constant water temperature $\left( \pm 0.5^{\circ} \mathrm{C}\right)$. The chamber volume was $1.5 \mathrm{~L}$. An ark shell was placed on a perforated, elevated platform in the center of the chamber, and a magnetic stir bar below the platform continuously mixed the water in the chamber. The oxygen consumption rate was measured using an oxygen measurement apparatus (915PDC; Istek, South Korea) as the difference in dissolved oxygen content in the chamber at the start and end of a $3 \mathrm{~h}$ incubation period. Ammonium excretion rates $(\mu \mathrm{g}$ $\mathrm{NH}_{3}-\mathrm{N} / \mathrm{g}$ wet wt./h) were measured for the same individual ark shells used to measure oxygen consumption rates. Water samples were taken from the chamber for the determination of ammonium concentrations using the phenolhypochlorite method (Solorzano, 1969) at the start and end of the $3 \mathrm{~h}$ incubation period.

Blood was taken from the heart area of ark shells using a $1 \mathrm{~mL}$ intravenous syringe to measure the amino acid content and osmolality. Of the sampled blood, $200 \mu \mathrm{L}$ were used to analyze osmolality using an osmometer (Osmomat 030; Genotec, Germany). The remainder of the blood was used to analyze the amino acid content using an amino acid analyzer (Biochrom 20 plus; Pharmacia UK).

To observe histological responses to decreases in salinity, the gill and mid-gut gland were fixed in Bouin's solution, and preparations were made using the paraffin method. Sections were stained using Mayer's hematoxylin-eosin (H-E) stain, alcian blueperiodic acid, Schiff's solution (AB-PAS, pH 2.5), and Long Ziehl-Neelsen stain. The median lethal salinity $\left(\mathrm{LS}_{50}\right)$ was determined using the probit method (Finney, 1971).

\section{Results}

\section{Survival rate}

When ark shells were exposed to various salinities at $25^{\circ} \mathrm{C}$ for 9 days, all individuals survived at salinities greater than 26.4 psu. However, only $15 \%$ of individuals survived at $13.2 \mathrm{psu}$, whereas most had died by the fifth day of exposure to 6.6 psu (Fig. 1). The 9-day $\mathrm{LS}_{50}$ of ark shells computed using the probit method (Finney, 1971) was 16.5 psu, with confidence limits of 14.9-18.1 psu (Table 1).

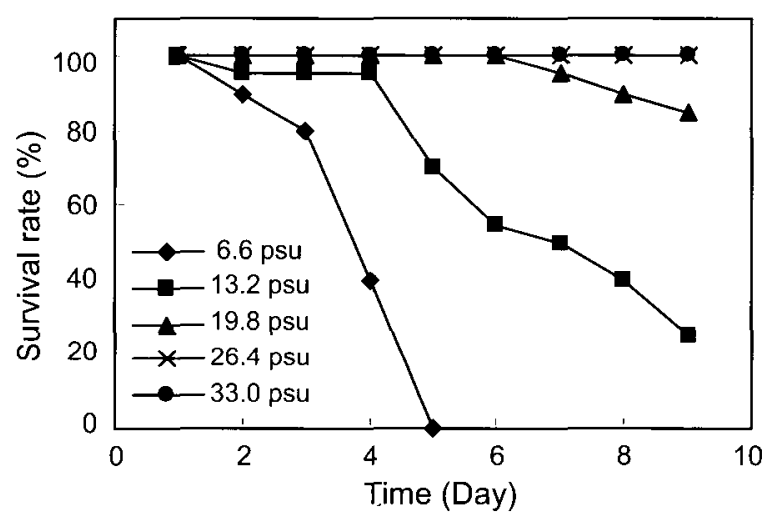

Fig. 1. Survival rate of the ark shell Scapharca broughtonii with decreasing salinity from $33.0 \mathrm{psu}$ to $6.6 \mathrm{psu}$ at $25^{\circ} \mathrm{C}$.

\section{Oxygen consumption rate}

The oxygen consumption rate of individuals exposed to a salinity of $33.0 \mathrm{psu}$ was fairly constant at $0.028 \pm 0.001 \mathrm{mg} \mathrm{O}_{2} / \mathrm{g}$ wet wt./h. In contrast, those exposed to salinities of $26.4 \mathrm{psu}$ and $19.8 \mathrm{psu}$ had relatively lower oxygen consumption rates of 0.017 and $0.011 \mathrm{mg} \mathrm{O}_{2} / \mathrm{g}$ wet wt./h, respectively, during the first 4 days of exposure. However, the oxygen consumption rate increased gradually on the fifth day of exposure and with decreasing salinity, reaching maximum oxygen consumption rates that were 19.3$32.2 \%$ higher than that of the control group in ordinary seawater. The oxygen consumption rates then decreased to levels similar to that of the control group.

The oxygen consumption rate of individuals ex- 
Table 1. Critical salinity range of ark shell, Scapharca broughtonii exposed to various salinities for 9 days at $25^{\circ} \mathrm{C}$

\begin{tabular}{ccccc}
\hline Temp. $\left({ }^{\circ} \mathrm{C}\right)$ & Acclimated salinity (psu) & Test salinity (psu) & No. killed & 9 day-LS (confidence limits) \\
\hline & & 6.6 & 20 & \\
25 & \multirow{2}{*}{33.0} & 13.2 & 17 & 16.5 (14.88-18.12) \\
& & 19.8 & 0 & \\
& & 26.4 & 0 &
\end{tabular}

posed to a salinity of 13.2 psu was $0.0057 \mathrm{mg} \mathrm{O} / \mathrm{g}$ wet wt./h during the initial stage of exposure, which was substantially lower than that of the control group. Although the rate increased slightly on the fifth dayof exposure, it continued to decrease after the fifth day and was the lowest among the groups (Fig. 2).

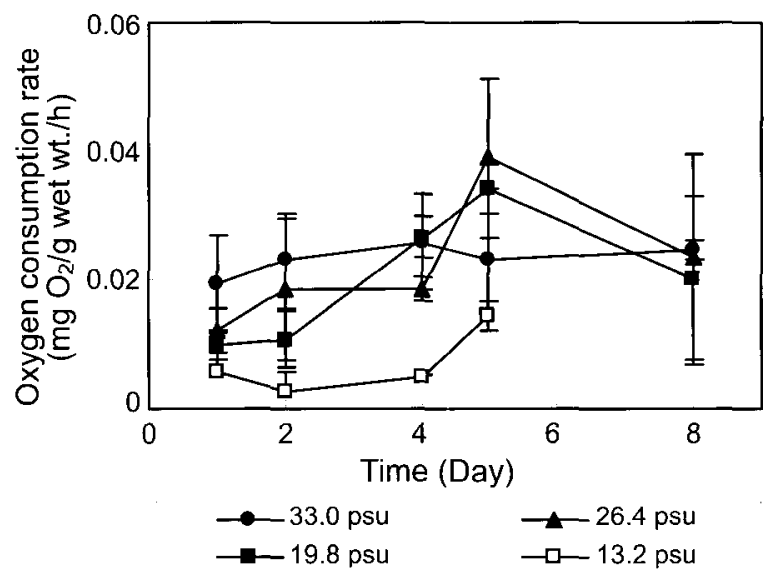

Fig. 2. Changes of the oxygen consumption rate in the ark shell Scapharca broughtonii exposed to decreasing salinity at $25^{\circ} \mathrm{C}$. Data points are means $\pm \mathrm{SD}$.

\section{Ammonium excretion rate}

In general, the rate of ammonium excretion increased in proportion to the reduction in salinity, with the exception of individuals exposed to a salinity of 13.2 psu (Fig. 3). The controls in ordinary seawater had an average ammonium excretion rate of $0.5 \mu \mathrm{g}$ $\mathrm{NH}_{3}-\mathrm{N} / \mathrm{g}$ wet wt./h throughout the experimental period. However, individuals exposed to salinities of $26.4 \mathrm{psu}$ and $19.8 \mathrm{psu}$ had higher ammonium excretion rates than those of the control group beginning on the first day of exposure. In contrast, individuals exposed to a salinity of 13.2 psu showed a slight increase in the ammonium excretion rate on the second day of exposure, but this decreased substantially to $0.0023 \mu \mathrm{g} \mathrm{NH}-\mathrm{N} / \mathrm{g}$ wet wt./h over time, which was the lowest among the groups (Fig. 3).

\section{Osmolality}

For individuals exposed to a salinity of $26.4 \mathrm{psu}$,

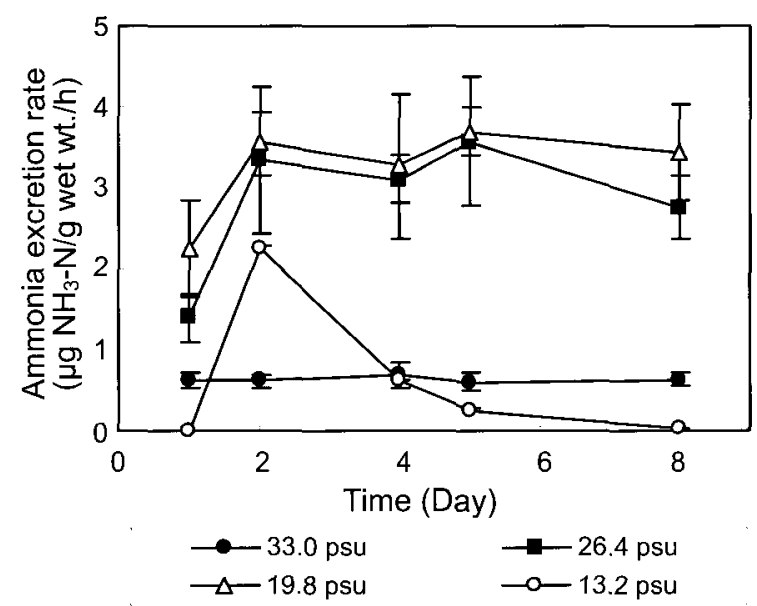

Fig. 3. Changes of the ammonium excretion rate in the ark shell Scapharca broughtonii exposed to decreasing salinity from 33.0 psu to $13.2 \mathrm{psu}$ at $25^{\circ} \mathrm{C}$. Data points are means \pm SD.

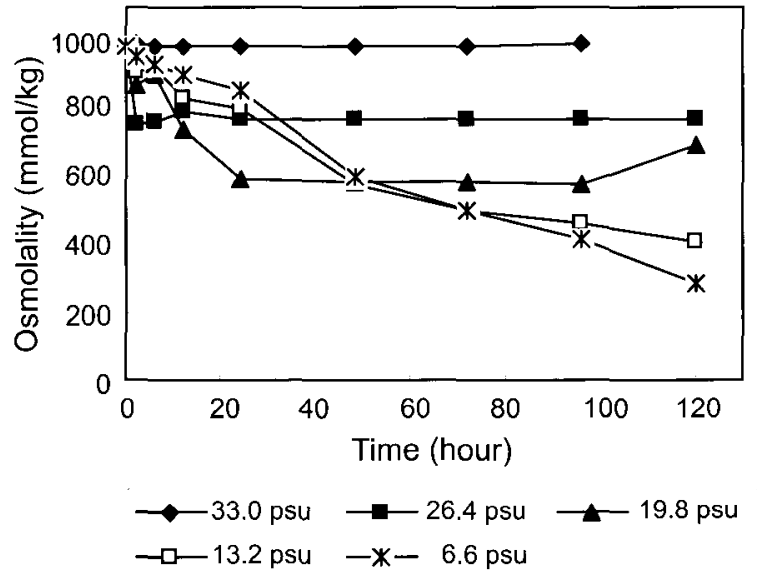

Fig. 4. Osmolality of the ark shell Scapharca broughtonii with decreasing salinity from $33.0 \mathrm{psu}$ to $6.6 \mathrm{psu}$ at $25^{\circ} \mathrm{C}$.

the osmolality was $770 \mathrm{osmol} / \mathrm{kg}$, illustrating acclimation to the osmolality of the surrounding seawater within $2 \mathrm{~h}$ of exposure (Fig. 4). Individuals exposed to a salinity of 19.8 psu displayed an osmolality of $692 \mathrm{osmol} / \mathrm{kg}$ and acclimated within $12 \mathrm{~h}$ of exposure. However, individuals exposed to salinities of 13.2 
psu and 6.6 psu acclimated more gradually than did the other groups. Although individuals exposed to a salinity of 13.2 psu acclimated by the fifth day of exposure, those exposed to a salinity of $6.6 \mathrm{psu}$ failed to acclimate, and all had died by the fifth day of exposure (Fig. 4).

\section{Changes in amino acids}

We examined changes in the concentrations of amino acids in the blood of ark shells on the fourth day of exposure to various salinities (Fig. 5). Taurine, alanine, and lysine were common in all animals; arginine, glutamine, histidine, and glycine were also detected. Taurine and alanine increased substantially in proportion to the reduction in salinity, whereas lysine decreased slightly.

\section{Histological responses to various salinities}

Changes in the mucous cells and epithelial cells were observed with changes in salinity (Figs. 6 and 7).

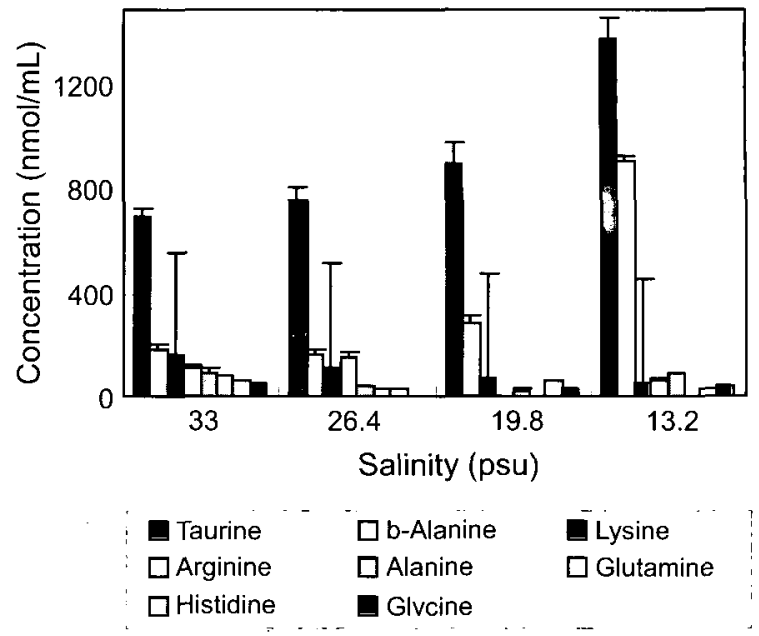

Fig. 5. Free amino acid concentration in the blood that were taken from ark shell Scapharca broughtonii acclimated to different salinities from 33.0 psu to $13.2 \mathrm{psu}$ at $25^{\circ} \mathrm{C}$. Data points are means $\pm \mathrm{SD}$.

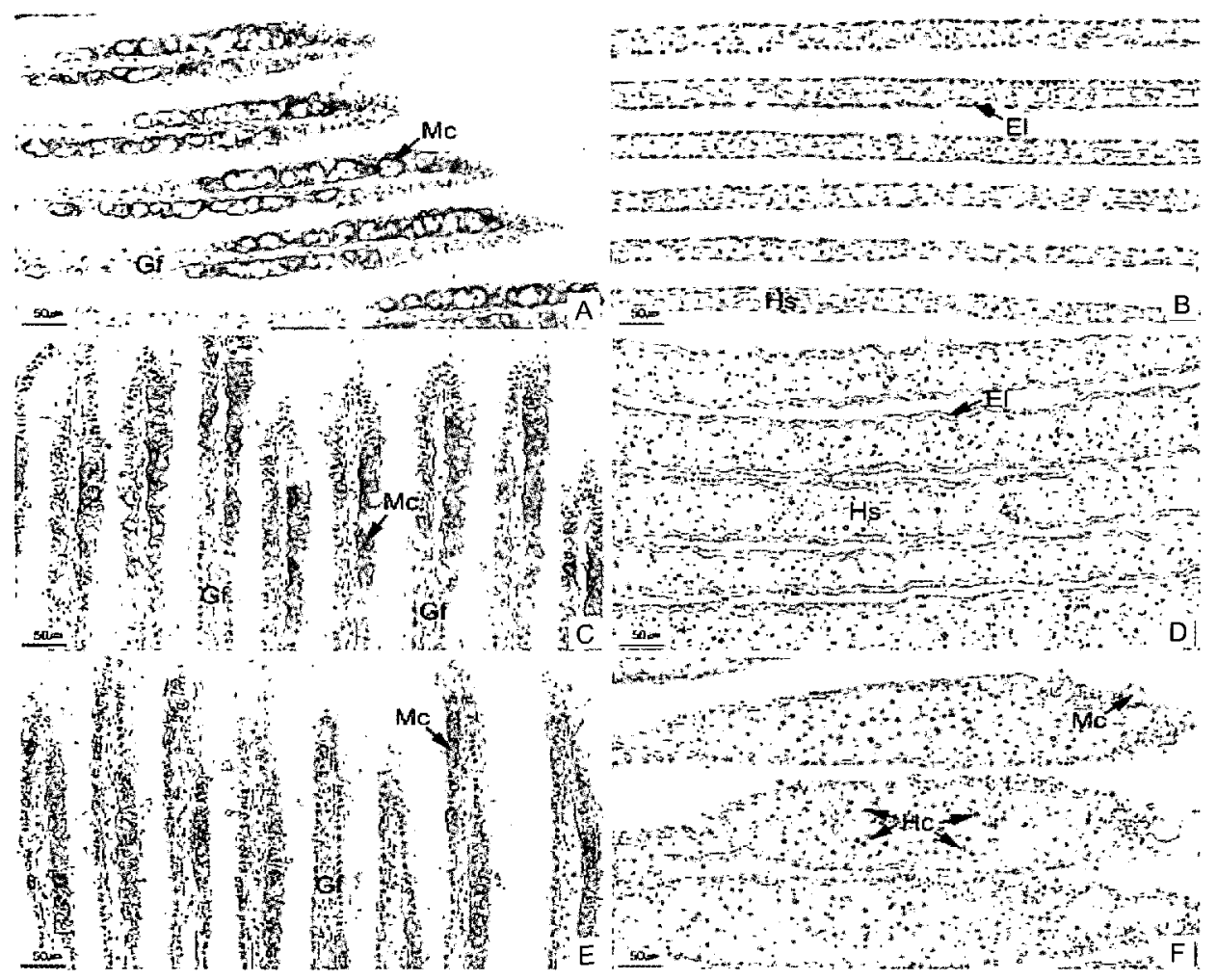

Fig. 6. Histological changes in the gill of ark shells Scapharca broughtonii exposed to various salinities for 9 days. A, Control. PAS-positive mucous cells (Mc) in the gill filament (Gf). AB-PAS (pH 2.5) reaction; B, Control. Epithelial layer of the simple squamous tissue of the filament. H-E stain; C, 26.4 psu. Acidic degeneration of mucous cells. AB-PAS ( $\mathrm{pH} 2.5$ ) reaction. D, 26.4 psu. Hypertrophy of the epithelial layer (El) and expanded hemolymph sinus (Hs). H-E stain; E, 19.8 psu. Atrophy and vacuolation of mucous cells. ABPAS (pH 2.5) reaction; F, 13.2 psu. Terminal clubbing of the filaments; Hc, hemocyte. 


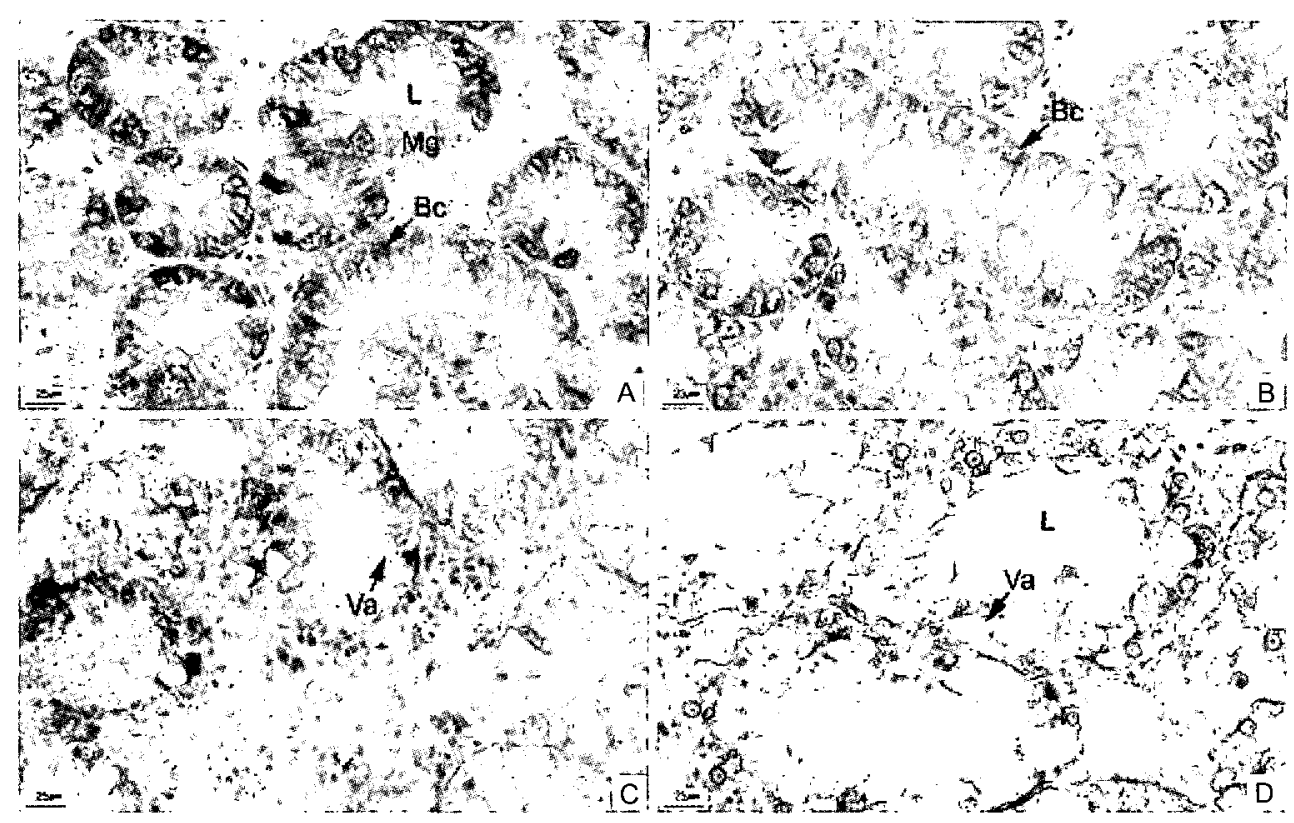

Fig. 7. Histological changes of the mid-gut gland in the ark shell Scapharca broughtonii exposed to different salinity for 9 days. H-E stain. A, Control. Section showing the tubular mid-gut gland (Mg) and basophilic cell (Bc); B, 26.4 psu. Reduction in stain affinity of basophilic cell; C, 19.8 psu. Atrophy and vacuolation of the gland; D, 13.2 psu. Vacuolation and deformation of the gland; L, lumen; Va, vacuole.

Changes in stain affinity from red to blue were observed in the mucous cells of the gill filaments using AB-PAS ( $\mathrm{pH} 2.5$ ) staining. This indicates that mucous characteristics changed from neutral to acidic.

Histological changes in the mucous cell included a decline in the number of mucous cells and conversion into vacuoles with decrease in salinity (Fig. 6). Furthermore, epithelial cells in the gill filaments changed from squamous to cuboidal, with some thickening of the epithelial layer, with decreases in salinity. The hemolymph sinus of the gill filament expanded due to increases in hemocytes along with such changes, and the gill filaments showed severe terminal clubbing (Fig. 6).

Histological changes with decreasing salinity were also observed in the mid-gut gland. The tubular shape of the mid-gut gland became less defined with decreasing salinity, and hypertrophy of the tubule epithelium, reduction in the stain affinity of basophilic cells, and an increase in vacuoles were observed. However, no accumulation of lipofuscin was observed (Fig. 7).

\section{Discussion}

The general response of shellfish to changes in the marine environment is a change in behavior and metabolic rate to maintain homeostasis. The phy- siological responses of marine organisms represent the sum of all cellular and biochemical reactions to the effects of environmental variables. For this reason, organisms are capable of reflecting deterioration in environmental conditions even before the effects are manifested in the population or community as a whole (Bayne et al., 1985). Shellfish are being studied from wide range of aspects, including survival, growth, metabolism, histological responses, enzymatic responses, and changes in blood properties, to establish the limits of the responses of organisms to environmental changes. Therefore, we examined changes in the survival and physiological responses of the ark shell from among the responses of organisms that are displayed in accordance with the changes in salinity that often occur in coastal areas due to frequent rainfall in summer. In general, salinity affects the physiological processes of marine organisms; typical responses to low salinity include reductions in food consumption and growth rates (Bohle, 1972; Widdows, 1985) and closure of the shell (Hand and Stickle, 1977; Shumway, 1977). In particular, shellfish in farms in coastal areas undergo various physiological changes in response to decreasing salinity during the rainy season, including a reduction in growth rate (Bohle, 1972) and increases in respiratory and excretion rates (Navarro and 
Gonzalez, 1998) because of physiological adjustments made by the organism to survive.

Abalone, Haliotis diversicolor supertexta, that have been acclimated at a salinity of $25 \mathrm{ppt}$ at $30^{\circ} \mathrm{C}$, can survive in salinities of 14-33 ppt (Chen and Chen, 2000 ); in contrast, those transferred from a salinity of $32.5 \mathrm{ppt}$ to lower salinities can endure a salinity of 20.5 ppt (Singhagraiwan et al., 1992). This range of salinity was similar to that in which ark shells acclimated at $33.0 \mathrm{psu}$ and $25^{\circ} \mathrm{C}$ could survive. However, for the manila clam, Ruditapes philippinarum, living in coastal regions of South Korea, the $\mathrm{LS}_{50}$ at $25^{\circ} \mathrm{C}$ is $19.2 \mathrm{psu}$ (Shin et al., 2000), indicating a slightly higher range of salinity tolerance compared to that of the ark shell. Thus, there are differences in the physiological state and tolerance to changes in salinity even among species that live in the same coastal area.

The oxygen consumption rate, which is used as a metabolic index, changes in various ways in organisms under physiological stress (Sastry and Varge, 1977). Almada-Villela (1984) reported that the oxygen consumption rate of organisms exposed to various ranges of environmental changes can either increase or decrease. Although the oxygen consumption rates of ark shells at salinities of 26.4 psu and 19.8 psu were lower than that of the control group at the initial stage of exposure, increases were detected from the fourth day and reached a range of 19.3$32.2 \%$ on the fifth day. Furthermore, the ammonium excretion rate increased in proportion to the reduction in salinity within the range of salinity tolerance, with the exception of the group exposed to a salinity of 13.2 psu. These levels were similar to oxygen consumption and ammonium excretion rates found in the Chilean scallop Argopecten purpuratus (Navarro and Gonzalez, 1998). For Mytilus edulis, whereas the oxygen consumption rate, filtration rate, and energy balance is maintained at 20-30 ppt, all physiological activity is reduced at salinities less than $20 \mathrm{ppt}$ (Widdows, 1985). Thus, although metabolic control in response to changes in salinity is possible within the physiological tolerance range, all metabolic rates and control abilities will decrease, and the individual will eventually die once the environmental conditions exceed the physiological tolerance range.

Food consumption and metabolic processes are reduced in response to changes in salinity at the initial stage of exposure. However, these are adjusted by gradually changing the osmolality within cells within 2-3 days, and the ark shell eventually recovers its normal functions (Widdows, 1985). The blood osmolality of ark shells transferred from a salinity of
33.0 psu to 26.4 psu and 19.8 psu acclimated within $12 \mathrm{~h}$. However, when transferred to salinities below $13.2 \mathrm{psu}$, the animals failed to acclimate and most died. This indicates that there are limits to physiological adjustments that can control the energy balance in response to dramatic changes in salinity over a short period of time (Widdows, 1985). Furthermore, during the period of exposure to low salinity, oxygen consumption and ammonia excretion increased following an initial reduction. Levels of taurine and alanine in the blood also increased substantially. Ammonia excretion also increased with reduced salinity in the Chilean scallop (Navarro and Gonzalez, 1998) and Mytilus edulis (Sadok et al., 1997); this was likely caused by an increase in protein catabolism to control the internal osmolality. In $M$. edulis, the increase in ammonia excretion was related to an increase in the concentration of amino acids in the hemolymph in relation to reduced salinity (Livingstone et al., 1979). The increase in taurine and alanine levels along with the increase in ammonia excretion in the ark shell was likely caused by osmotic adjustments during exposure to low salinity. The initial reduction in oxygen consumption was due to anaerobic metabolism. Alanine is an important end product of anaerobic metabolism in shellfishes (Zwaan and Zandee, 1972). Because the oxygen consumption rate was low prior to acclimation to decreased salinity in the ark shell, and taurine and alanine levels increased, an-aerobic metabolism likely occurred in the initial stage of exposure.

In summary, the salinity tolerance range of ark shells at $25^{\circ} \mathrm{C}$ was $14.9-18.1$ psu. Ark shells can likely survive at salinities above 16.1 psu using various physiological mechanisms. South Korea experiences heavy and concentrated rainfall in the summer, and the salinity of coastal areas during this period falls below 10 psu for several days. During this period, mass mortality of shellfishes in farms in coastal areas frequently occurs due to high water temperatures and low salinities. However, more research on this subject is required. Our results will provide important fundamental information for examining the causes of death of shellfish in the summer.

\section{Acknowledgements}

This study was supported by the South Sea Fisheries Research Institute in the National Fisheries Research and Development Institute (RP-2006-AQ019). 


\section{References}

Almada-villela, P.C. 1984. The effects of reduced salinity on the growth of small Mytilus edulis. J. Mar. Biol. Assoc. UK, 64, 171-182.

Bayne, B.L., D.A. Brown, K. Burns, D.R. Dixon, A. Ivanovici, D.R. Livingstone, D.M. Lowe, M.N. Moore, A.R.D. Stebbing and J. Widdows. 1985. The effects of stress and pollution on marine animals (Praeger special studies). Praeger Scientific, Westport, CT., 3-39.

Bohle, B. 1972. Effects of adaptation to reduced salinity on filtration activity and growth of mussels (Mytilus edulis). J. Exp. Mar. Biol. Ecol., 10, 41-49.

Chen, J.C. and W.C. Chen. 2000. Salinity tolerance of Haliotis diversicolor supertexta at different salinity and temperature levels. Aquaculture, 181, 191-203.

Finney, D.J. 1971. Probit Analysis, 3rd ed. Cambridge University Press. London, 1-333.

Hand, S.C. and W.B. Stickle. 1977. Effects of tidal fluctuations of salinity on pericardial fluid composition of the American oyster (Crassostrea virginica). Mar. Biol., 42, 259-271.

Kinne, O. 1966. Physiological aspects of animal life in estuaries with special reference to salinity: Neth. J. Sea Res., 3, 222-244.

Livingstone, D.R., J. Widdow and P. Feith. 1979. Aspects of nitrogen metabolism of the common mussel (Mytilus edulis): adaptation to abrupt and fluctuating changes in salinity. Mar. Biol., 53, 41-45.

Navarro, J.M. and C.M. Gonzalez. 1998. Physiological responses of the Chilean scallop (Argopecten purpuratus) to decreasing salinities. Aquaculture, 167, 315-327.

Pierce, S.K and M.J. Greenberg. 1972. The nature of cellular volume regulation in marine bivalves. J. Exp. Biol., 57, 681-692.

Sadok, S., R.F. Uglow and S.J. Haswell. 1997. Haemolymph and mantle fluid ammonia and ninhydrin positive substance variation in salinity-challenged mussels (Mytilus edulis L.). J. Exp. Mar. Biol. Ecol., 212, 195-212.

Sastry, A.N. and S.L. Varge. 1977. Variations in the physiological response of crustacean larvae to temperature. In: Physiological response of marine biota to pollutants. Vernberg, F.J., A. Calabrese, F.P. Thurberg, W.B. Vernberg, eds. Academic Press, New York, 410424.

Shin, Y.K., Y. Kim, E.Y. Chung and S.B. Hur. 2000. Temperature and salinity tolerance of the Manila clam (Ruditapes philippinarum). J. Kor. Fish. Soc., 33, 213-218.

Shumway, S. 1977. The effects of fluctuating salinity on the tissue water content of eight species of bivalve mollusks. J. Comp. Physiol., 116, 269-285.

Singhagraiwan, T., M. Doi and M. Sasaki. 1992. Salinity tolerance of juvenile donkey's ear abalone, Haliotis asinina Linne. Thai Mar. Fish. Res. Bull., 3, 71-77.

Solorzano, L. 1969. Determination of ammonia in natural waters by the phenolhypochlorite method. Limnol. Oceanogr., 14, 799-801.

Tucker, L.E. 1970. Effects of external salinity on Scutus breviculus (Gastropoda, Prosobranchia)-I. Body weight and blood composition. Com. Biochem. Physiol., 36, 301-319.

Widdows, J. 1985. The effects of fluctuating and abrupt changes in salinity on the performance of Mytilus edulis. In: Marine Biology of Polar Regions and Effects of stress on marine organism. Gray, J.S. and M.E. Christiansen, eds. Wiley-Interscience, 555-566.

Zwaan A. and D. I. Zandee. 1972. The utilization of glycogen and accumulation of some intermediates during anaerobiosis in Mytilus edulis L.. Comp. Biochem. Physiol., 43B, 47-54.

(Received September 2006, Accepted December 2006) 